\title{
Low COVID-19 Infection and Mortality in Rice Eating Countries
}

\author{
Shaw Watanabe ${ }^{1 *}$ and Kazumoto Inuma ${ }^{2}$ \\ ${ }^{1}$ Life science Promoting Association, Asia Pacific Clinical Nutrition Society, Japan \\ ${ }^{2}$ Ricetech Corporation, Japan
}

*Corresponding author: Shaw Watanabe, Life science Promoting Association, Asia Pacific Clinical Nutrition Society, Tokyo, Japan

\begin{abstract}
The relationship between rice consumption and the cumulative number of COVID-19/1000000 at June 6, 2020 was examined after compilation of data from 19 major countries on 5 continents. A strong negative correlation with a coefficient of determination of 0.59 was found. On the contrary, wheat consumption showed the positive correlation. This suggests that resistance to SARS-CoV-2 infection is influenced by the nature of staple foods. This is compatible with previous findings indicating that rice eaters have a specific profile of intestinal microbiota, which strengthens the innate immunity to virus infection. Lower infection rates in Asia than in the West appear to be partly due to dietary differences. Improvements in agricultural policies and eating habits, especially the promotion of the use of brown rice food and rice bran, should be part of the national strategies to counter the COVID-19 pandemic.
\end{abstract}

Keywords: COVID-19; Innate Immunity; Rice; Brown Rice; Wheat

\section{Introduction}

"Let food be thy medicine and medicine be thy food." This quote is attributed to Hippocrates in ancient Greece. The idea of a link between medicine and food stems from the concept of common grounds for illness, health, and diets. This thinking permeates all popular cultures, fitting in very nicely with an historical phenomenon. Recently, this concept has broadened our scientific horizon, and appears to apply to the case of COVID-19 infection as well [1]. Staple foods of the world are roughly divided into those made from rice and or wheat. Rice is popularly used in Asia, and wheat is used in Europe and America. To test the hypothesis that dietary differences play a role in the immunity to COVID-19 infection, we looked for a possible correlation between rice consumption, and SARS-CoV-2 virus infection and mortality.

\section{Methods, Data and Statistical Analysis}

Country data on the daily incidence of cases and deaths (per 1 million inhabitants) caused by COVID-19 are publicly available $[2,3]$. The reference data were set at June 6, 2020. For correlation analysis, we selected a sample of 19 representative countries, distributed over 5 continents (Table 1). Of these countries, 18 are members of the G20 (Group of Twenty). Additional data from Spain was adopted. For the same countries, per capita consumption of rice and wheat (kg/year) were taken as independent variables. The source of food data is [worldfood.apionet.or.jp/web/9-1.htm]/jt, and data of 1998 were used [4]. The two variables were subjected to regression analysis after common logarithmic transformation. Correlations were calculated by the least square's method by IBMSPSS ver.24.

Table 1: Selected countries by continent, and COVID-19 incidence as of June 6, 2020.

\begin{tabular}{|c|c|}
\hline $\begin{array}{c}\text { North/Central/South } \\
\text { America: }\end{array}$ & Canada, USA, Mexico, Argentina. \\
\hline Europe: & $\begin{array}{c}\text { United Kingdom, France, Italy, Germany, } \\
\text { Spain, Russia. }\end{array}$ \\
\hline Asia: & China, Japan, India, Indonesia, South Korea, \\
\hline $\begin{array}{c}\text { Africa/Middle East/ } \\
\text { Australia: }\end{array}$ & $\begin{array}{c}\text { South Africa, Turkey, Saudi Arabia, and } \\
\text { Australia. }\end{array}$ \\
\hline
\end{tabular}




\section{Relationship between Per Capita Rice Consumption and Cumulative Number of COVID-19 Patients by Country}

Figure 1 shows the rice consumption per capita (kg/year) on the horizontal axis and the number of COVID-19 infected people per million population on the vertical axis. Both axes are logarithmic. The coefficient of determination is 0.592 , confirming a negative correlation. The mortality rate shows a weaker correlation $(0.44)$ than the number of infected people, because the mortality data is independently affected by medical care and other conditions (Figure 2).

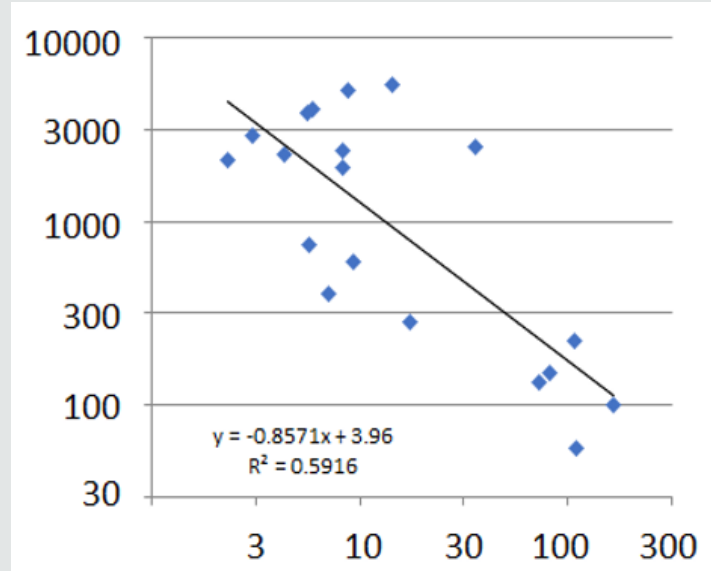

Figure 1: Scatter plots between number of COVID-19 patients and rice consumption per capita. Y-axis; Number of COVID-19 patients/million, $\mathrm{X}$-axis; rice consumption/ capita $\mathrm{kg} /$ year.

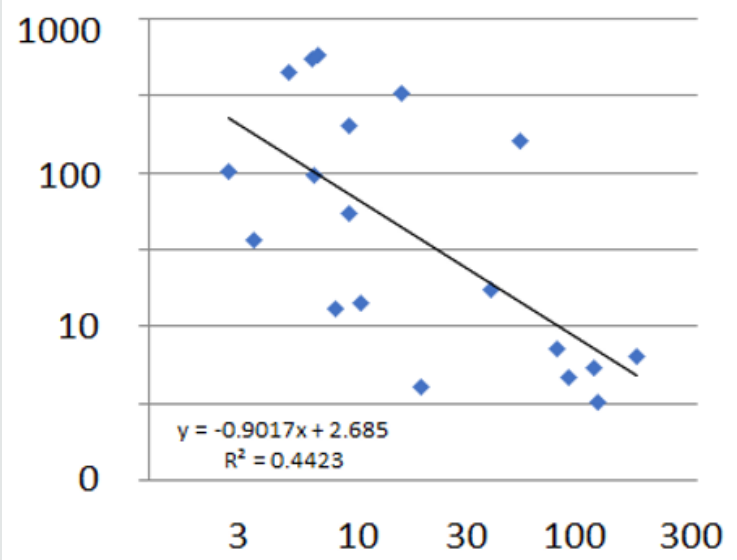

Figure 2: The scatter plot between the number of deaths per one million population and rice consumption per capita. Y-axis; Number of COVID-19 deaths/million, $\mathrm{X}$-axis; rice consumption/capita $\mathrm{kg} /$ year.

\section{Correlation between Wheat Consumption and the Number of COVID-19 Cases}

The correlation between the number of COVID-19 patients and the wheat consumption (kg/year) by country shows the positive correlation in contrast to the rice consumption. The correlation with wheat consumption is positive, quite contrary to rice, but the coefficient of determination is 0.49 , which is smaller than Rice (Figure 3)

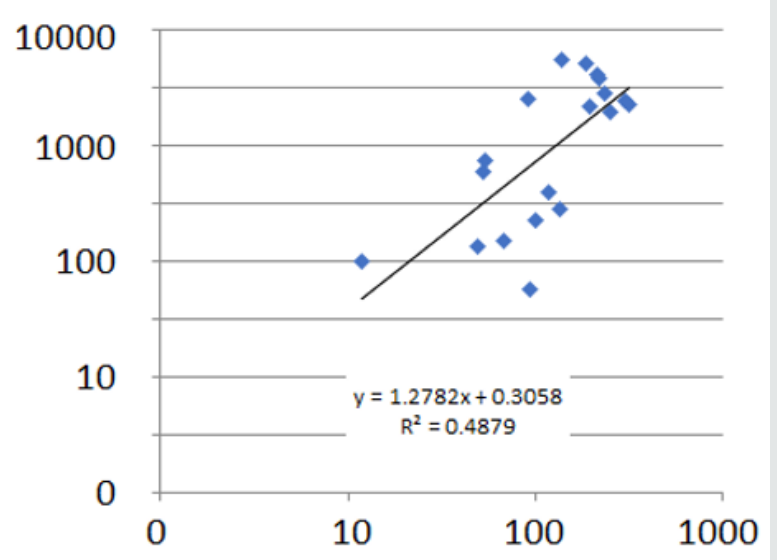

Figure 3: Scatter plot of wheat consumption by country and the number of COVID-19 patients. Y-axis; Number of COVID-19 patients/million, X-axis; wheat consumption/ capita $\mathrm{kg} /$ year.

\section{Discussion and Conclusion}

The magnitude of the new coronavirus epidemic varies greatly from country to country. Why is the Japanese population less frequently infected? Why are there so many cases in America? Why are the situations of Asia and Europe so different? It seems that there has never been a model that can answer these questions consistently. We proposed a hypothesis that the high proportion of sIgA deficiency among Caucasians would be one explainable factor [1]. This time we conducted a statistical analysis by scatter plot of the correlation between staple food and coronavirus infection. The coefficients of determination between the number of infected people or the number of deaths, and rice consumption showed negative correlations of 0.59 and 0.44 , respectively. Moreover, there was a positive correlation with wheat consumption. Such a big contrast could cover the effects of many other confounding factors, and strongly support the importance of innate immunity based on rice foods. These results suggest that rice eaters have an intestinal environment characterized by a special microbiota composition, whereby secreted short chain fatty acids stabilize the innate immunity by T17/Treg balance $[5,6]$. It appears that the Asian-type meal centered on rice and fish provides more resistance to virus infection than the Western-type meal centered on bread and meat. Among rice foods, it has been known that ingestion of brown rice and rice bran contributes greatly to health [7]. These methods could be employed for population-based prevention of the second wave COVID-19 pandemic in developed countries, and those still spared from the spread of corona virus infection in developing countries $[8,9]$. 


\section{Acknowledgement}

The authors deeply appreciate Dr. Philippe Calain for his sincere discussion and editing of this manuscript.

\section{References}

1. Watanabe S, Naito Y, Yamamoto T (2020) Host Factors That Aggravate COVID-19 Pneumonia. Int J Fam Med Prim Care 1(3): 1011-1014.

2. Idogawa $\mathrm{M}$, Tange $\mathrm{S}$, Nakase $\mathrm{H}$, Tokino $\mathrm{T}$ Interactive Web-based Graphs of Coronavirus Disease 2019 Cases and Deaths per Population by Country, Clinical Infectious Diseases, ciaa500, https://doi.org/10.1093/ cid/ciaa500.

3. Word wide daily incidence of infection by the new coronavirus. Department of Medical Genome Sciences, Research Institute for Frontier Medicine, Sapporo Medical University School of Medicine June 4, 2020.

4. Ito S (2020) Per capita consumption of rice, wheat and corn in the world and their changes. Kyushu University. Faculty of Agriculture. World Food Statistics and Graphics. worldfood.apionet.or.jp/web/9-1.htm.
5. Hirakawa A, Aoe S, Watanabe S, Hisada T, Mocizuki J, et al. (2019) The nested study on the intestinal microbiota in GENKI Study with special reference to the effect of brown rice eating. J Obes Chronic Dis 3(1): 1113.

6. Furusawa Y, Obata Y, Fukuda S, Endo T, Nakato G, et al. (2013) Commensal microbe-derived butyrate induces the differentiation of colonic regulatory T cells. Nature 504(7480): 446-450.

7. Watanabe S, Hirakawa A, Mizuno S, Wakino S, Adachi K (2020) What should we eat for healthy longevity? Necessity of tailor-made nutrition. Acta Scientific Nutritional Health 4(3): 01-05

8. Watanabe S (2020) MicroRNA opens up a new world for nutrition research. Acta Scientific Nutritional Health 4(1): 38-39.

9. Editor's note. Leaving lockdown means understanding immune responses to the virus. Science and Technology, 2020. https://www. economist.com/science-and-technology/2020/05/02/leavinglockdown-means-understanding-immune-responses-to-the-virus

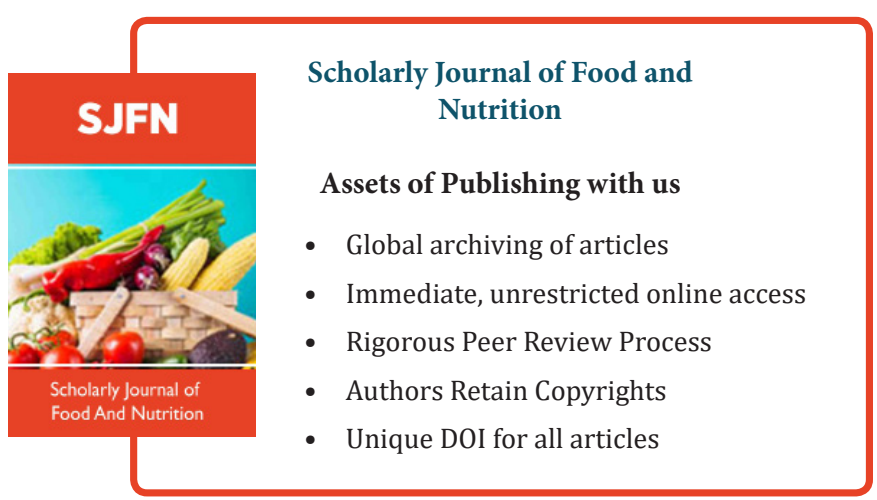

